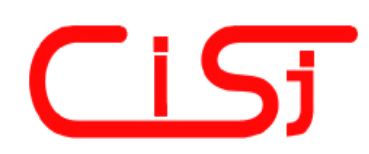

\title{
DIGITAL SIGNAL CHAINS IN PARTIAL DISCHARGE MEASUREMENT *
}

\author{
Josef Vedral, Martin Kriz, Karel Zalis \\ Czech Technical University in Prague, Technická 2, 16627 Prague \\ vedral@fel.cvut.cz,krizm@fel.cvut.cz, zalis@fel.cvut.cz
}

\begin{abstract}
The paper presents digital techniques in partial discharge measurement. The discharge current pulses are measured on high voltage machines such as power plant generators and transformers. The presented modern digital techniques are suitable for all measurement where impulse energy will be calculated.
\end{abstract}

Keywords: partial discharge meter, current pulses, high voltage machines, digitalization, non-correlated sampling.

\section{INTRODUCTION}

A Partial Discharge (PD) is a phenomenon which occurs in high voltage insulation systems. This phenomenon is a discharge in void or cavity in an insulation layer. The discharge breaks only small portion of a dielectric layer. It does not affect the momentary dielectric strength neither momentary breakdown voltage. The dielectric strength and breakdown voltage of the dielectric layer are affected and lowered by the repetitive PD activities. These long term PD activities will be monitored and the results will be used for diagnostic purposes and for repairs planning.

There is lot of non-electric methods for PD monitoring such as chemical and optical analysis [1], thermo vision, rf power spectral evaluation [2], ultrasonic [3], [4] and [5]. One of the sophisticated and standardized method is a "galvanic method" [6], [7]. The method is based on the voltage pulses measurement on machine terminals. This method is suitable for on-line diagnostic, because it is not necessary to insert any special probe or sensor inside machine windings or the presence of specialized equipment is not essential. The method uses the standard high voltage components for coupling the meter.

The key parameter for partial discharge monitoring is an image charge. The charge is called "image charge" because real charge is inaccessible inside machine windings or insulation layers. The PD meters are calibrated with partial discharge calibrators in parallel with machine terminals - the readout of the PD meters corresponds only to "image charge" not to real charge inside electric machine. The relation

\footnotetext{
* This paper was selected by Vladimir Oleshchuk and Dominique Dallet, IPC Co-Chairmen of IDAACS'09 Workshop, www.idaacs.net
}

between partial discharge and image charge is discussed in [1] and [13].

The representative input circuit of discharge meters is shown in Fig.1.

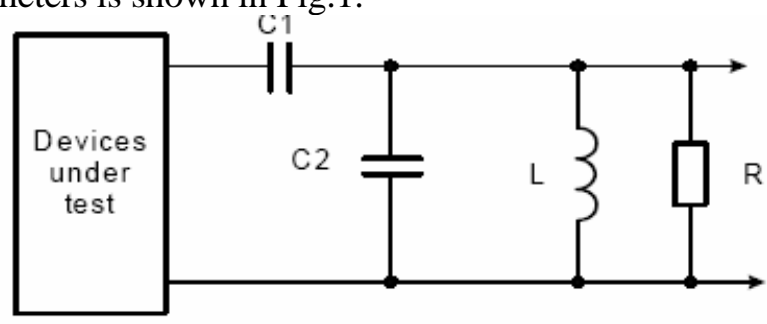

Fig. 1 - Standard input circuits of discharge meter

A capacitance divider $C_{1}, C_{2}$ is used for the high voltage. Reduction The voltage divider ratio $p$ can be expressed by next formula in frequency range from $30 \mathrm{kHz}$ to $500 \mathrm{kHz}$. The typical values of the components: $C_{1}=1 \mathrm{nF}, \quad C_{2}=150 \mathrm{nF}, \quad L=2.5 \mathrm{mH}$, $R=1 \mathrm{k} \Omega$.

$$
p \approx \frac{C_{1}}{C_{1}+C_{2}}
$$

Voltages and current wave in dielectric layer are illustrated on Fig.2.

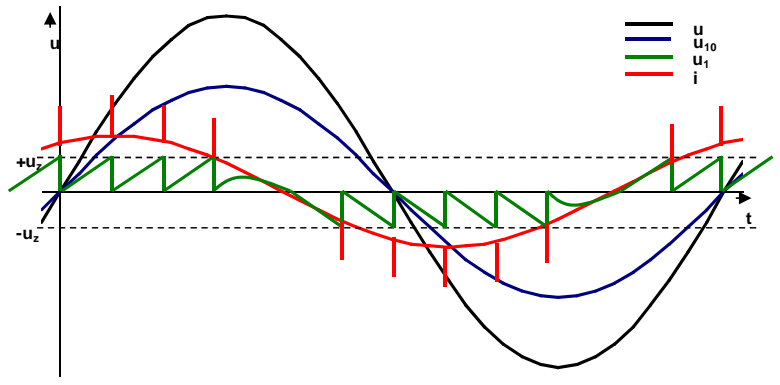

Fig. 2 - Time plot of driving and void voltage, current trough the dielectric layer 
Voltage $u$ is main driving voltage of dielectric layer. The voltage $u_{10}$ is a voltage on void in insulation dielectric layer, without a discharge. The voltage $u_{1}$ corresponding to partial discharge in void illustrates discharge if ignition voltage $u_{\mathrm{z}}$ is reached. Because the stored energy in void capacitance is discharged, the void will be charged again to the ignition voltage. A power source current $i$ contain the spikes corresponding to discharge events.

The current spikes are measured and displayed indirectly. The decreasing voltage pulses are measured on the main machine impedance. The tester is connected on the machine terminals.. The input circuit separates the discharge events, transformed to the voltage pulses, from high voltage and low frequency components.

The input circuit will be designed carefully, because it will separate high voltage $6 \mathrm{kV} / 50 \mathrm{~Hz}$ and higher voltages from sensitive semiconductor circuits. The separated signal will be integrated or filtrated for the image charge evaluation.

\section{PARTIAL DISCHARGE FREQUENCY SPECTRUM}

The standardized partial discharge impulse [1] has rising time $T_{1}$ up to $60 \mathrm{~ns}$ and exponential fall time $T_{2}$ to the half of the maximum about 120 ns, Fig.3.

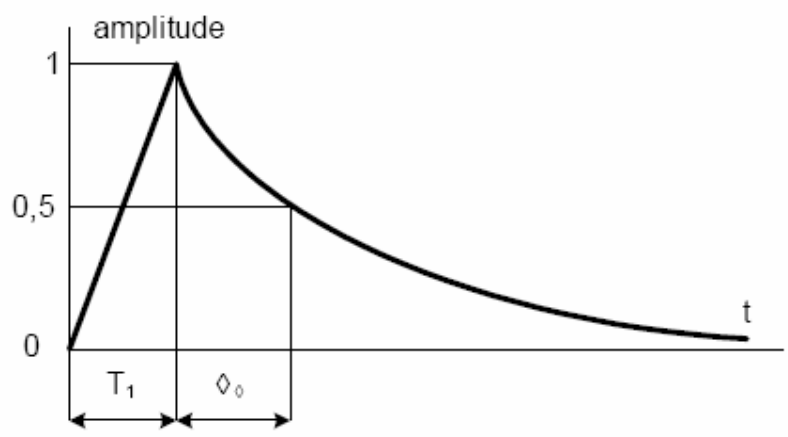

Fig. 3 - Partial discharge impulse

\section{TRADITIONAL PARTIAL DISCHARGE MEASUREMENT TECHNIQUES}

Traditional partial discharge measurement chains are based on analogue filters and peak detection circuits. Captured maximal levels from peak detection circuit are shown on analogue oscilloscope screen.

This technique is not suitable for on-line diagnostic purposes; because there is necessary a highly experienced and educated staff assistance. The better way for on-line diagnostic is digitizing captured values from peak detector and sending the values for processing in diagnostic software.

\section{IMPROVED PARTIAL DISCHARGE MEASUREMENT TECHNIQUE}

The major improvement of the traditional PD measurement chain [8] is usage of the logarithmic amplifier in combination with analog to digital converter (ADC) [10], [11]. The benefit of this method is the dynamic range compression and signal processing of captured data, see Fig.4.

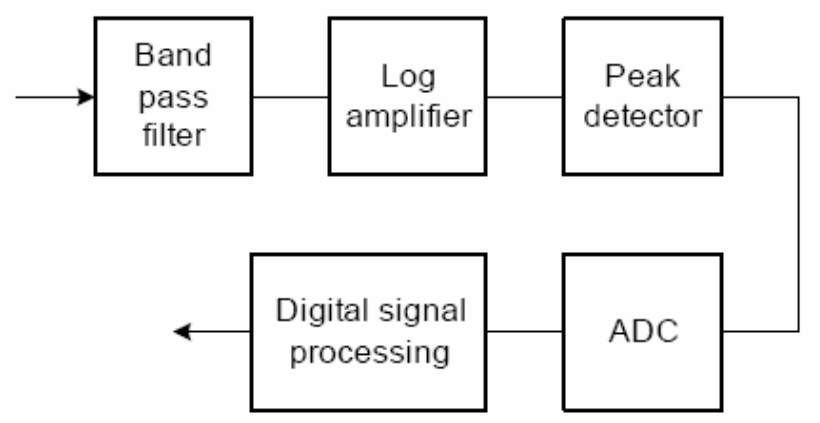

Fig. 4 - Improved partial discharge meter with logarithmic amplifier peak detector and ADC

The PD pulses spectrum is limited by band pass passive filter. The dynamic range is compressed in logarithmic amplifier. Maximal values are captured by the peak detector. The captured values are digitized by the ADC and processed in the digital processing circuit [12]. The sampling frequency is not in relation with input signal.

The detector is reset on demand [9]. In presented PD meter samples the peak detector is reset 256 times in mains power period. The sampling frequency is $12800 \mathrm{~Hz}$ for $50 \mathrm{~Hz}$ mains voltage frequency. Also the 10 times higher frequency is used for software synchronization purposes with external signal. The synchronization provides service for partial discharge source localization in electric machine windings [14], [15].

\section{FULLY DIGITAL PARTIAL DISCHARGE MEASUREMENT TECHNIQUES}

The digital techniques are based on using high precision and high speed ADC and digital filters. Two base approaches can be recognized: To measure the full spectra of impulse signal (rising times in nanosecond). It means to digitize signal with gigahertz frequency range. Or to digitize narrowband signal in boundaries as it is defined in international standard [1].

The partial discharge charge will be computed in two ways: computing maximal value in narrowband signal and computing the digitized wideband signal area. 


\section{PARTIAL DISCHARGE SYSTEM WITH CHARGE COMPUNTIG FROM IMPULSE AREA}

The fully digital PD measurement chain is very simple. It's only ADC with anti-aliasing filter and following digital signal processing circuit inside field programmable gate array (FPGA) or other specialized circuit, Fig.5.

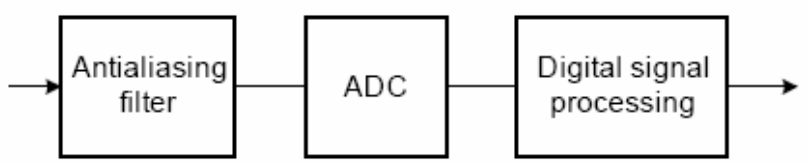

Fig. 5 -A fully digital wideband partial discharge meter

The simplicity of the chain has only one problem with wideband signal nature, because the signal rising edges are from several nanoseconds for solid dielectric systems and several tens of nanoseconds for liquid insulating mediums. It means the ADC will digitize the signal in range of half gigahertz. The physical realization of this type of measurement chains are really challenges in electronic circuits design. The sources of uncertainties in the fully digital signal chain are the passive anti-aliasing filter uncertainties, ADC uncertainties (gain and offset error, the integral nonlinearity influences, effective number of bits) non- correlated sampling frequency with PD pulses and errors in digital signal processing like rounding.

\section{UNCERTAINITY OF AREA COMPUTING FROM NON-CORELLATED SAMPLING}

Non-correlated sampling frequency with PD events is one of the uncertainty sources during sampling, ADC conversion and area computation process, see Fig.6.

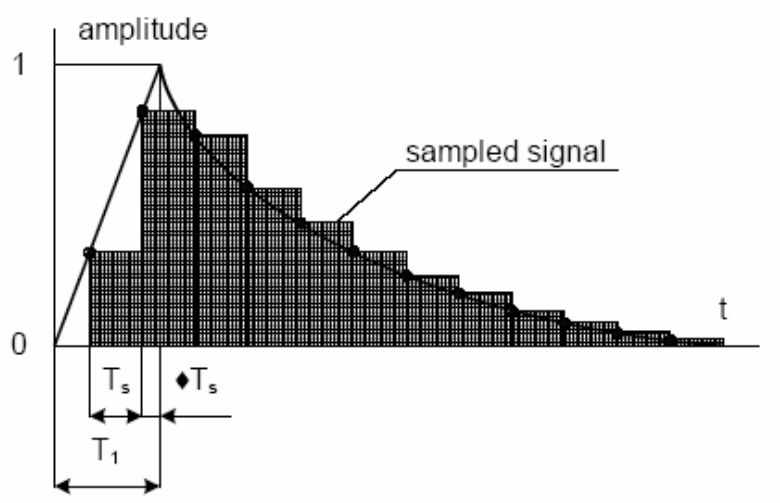

Fig. 6 - Charge uncertainty from non correlated sampling
This kind of the uncertainty can be computed as a variation between ideal computed area by the continuous integration $S_{\text {int }}$ and by the summation $S_{\text {sum }}$ of the ADC sampled data. The results are dependent on pulse shape and on summation algorithm for area computing.

A simple case: pulse has a linear rise to the maximal value. In time $T_{\mathrm{r}}$ and it falls exponentially with constant $\tau, f_{\mathrm{s}}$ is sampling frequency, $\Delta T_{\mathrm{s}}$ is a delay-of-maximal-value from sampling time and $\delta T_{\mathrm{s}}$ is a relative value of $\Delta T_{\mathrm{s}}$. The uncertainty can be computed from the equations (1) and (2),

$$
\begin{aligned}
& S_{\mathrm{int}}=\frac{1}{T_{r}} \int_{0}^{T_{r}} t d t+\int_{t_{r}}^{\infty} e^{-\frac{t-T_{r}}{\tau}} d t=\frac{T_{r}}{2}+\tau \\
& S_{\text {sum }} \approx \frac{T_{s}}{2 T_{r}}\left[M^{2}+3 M-2 \delta T_{s}(M-1)\right]
\end{aligned}
$$

Were $M$ is integer part of division $T_{\mathrm{r}} / T_{\mathrm{s}}$ is the decimal fraction of division $T_{\mathrm{r}} / T_{\mathrm{s}}$. The uncertainty is computed as a difference between $S_{\text {int }}$ and $S_{\text {sum, }}$ Fig.7.

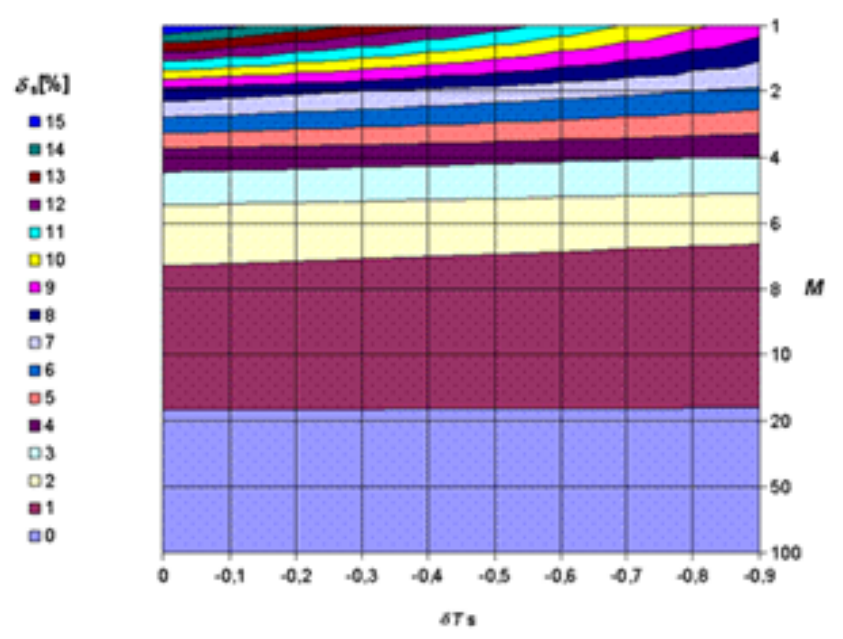

Fig. 7 - Chart of charge relative uncertainty $\delta_{s}$ on ADC sampling offset $\delta T_{s}$ and rate $M$

\section{UNCERTAINITY OF PEAK VALUE RECOGNITION FROM LATED SAMPLING FREQUENCY WITH PD EVENTS}

The PD event amplitude will be computed in the case if software peak detection will be used. In this case other source of uncertainty can be identified. The maximal difference between the peak value and the sampled and non-correlated the PD meter input value. Sampling period $T_{\mathrm{S}}$ is in relation (5), $T_{\mathrm{r}}$ is an impulse rise time, $f_{\mathrm{h}}$ is an impulse upper frequency, $F S_{\mathrm{AD}}$ is a full scale of the ADC. 


$$
\frac{d u}{d t_{\max }}=\frac{0,8 F S_{A D}}{T_{r}}=2,29 F S_{A D} f_{h}
$$

The uncertainty $U_{\text {BADM }}$ represents difference between sampled peak value of impulse and actual peak value of the impulse in relation between the impulse highest frequency $f_{\mathrm{h}}$ and the sampling frequency $f_{\mathrm{s}}$.

$$
u_{B A D M}=\frac{\Delta_{A D M}}{2 \sqrt{3}}=0.66 F S_{A D} \frac{f_{h}}{f_{s}}
$$

\section{HARDWARE DESIGN}

For development of the PD meter sample [11] based on improved analog technique. The wideband logarithmic amplifier (DC- $350 \mathrm{MHz}$ ) the demodulating logarithmic amplifier from Analog devices AD8307 (with 88dB dynamic range) is used. The microprocessor (Analog Devices ADUC814) is equipped with a 12 bit, $5 \mu$ sec ADC. The sample has rugged construction with surge arrester combined with clamping diodes on input and galvanic isolated RS232 communication line with heavy duty transient suppressors on its output.

\section{RESULTS}

For evaluation purposes the hardware sample of PD meter based on improved analogue technique was developed [10], [11] and [12]. The fully digital PD meters are pre-evaluated using the state of the art monolithic integrated circuits. However the parameters of the digital PD meter are only computed and they are not proved in praxis. The traditional PD meter is published only for reference.

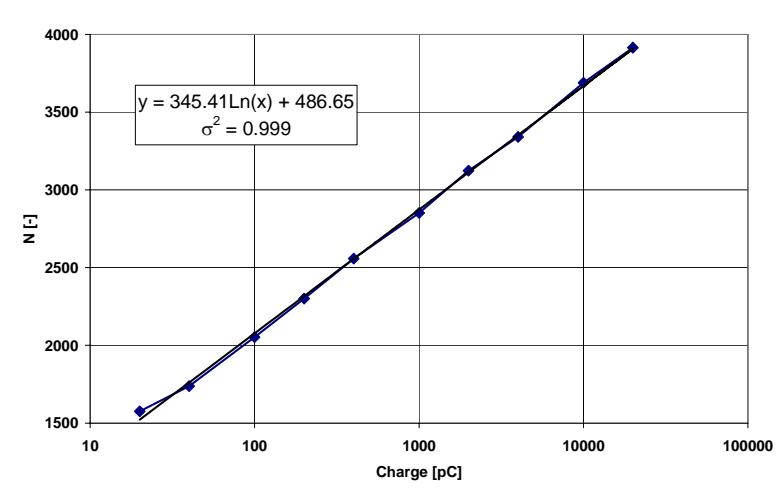

Fig. 8 - Partial discharge meter transfer characteristic

The major improvement is absence of attenuation switching matrix for range changing and online communication with master computing system.

The screenshot of the controlling software is on Fig.9. The software controls PD meter, provides calibration, two alarm levels control and it has interface, which links user with expert system based on rules and neural network for PD activity evaluation.

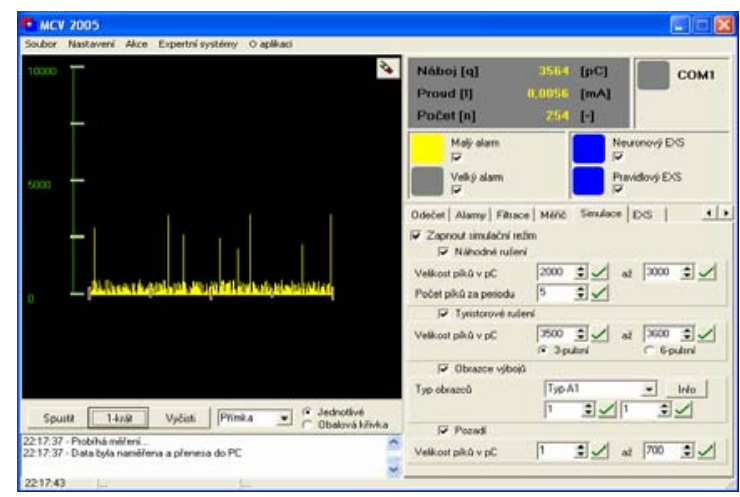

Fig. 9 - Partial discharge meter controlling software

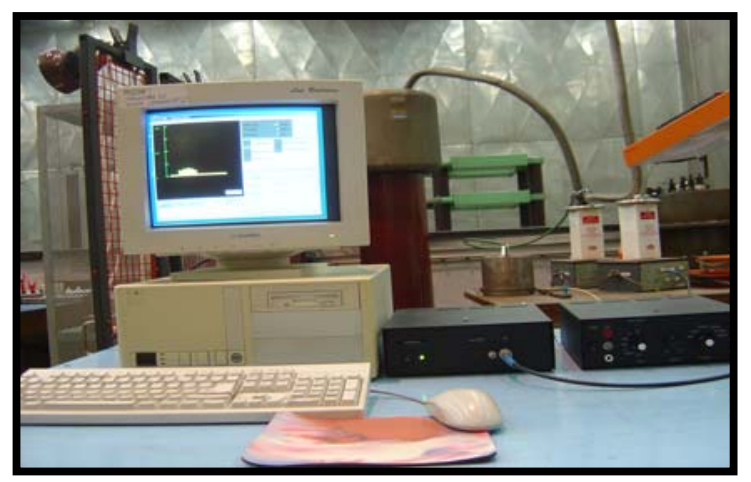

Fig. 10 - Workspace overview in high voltage laboratory

The major parameters of the PD meters based on described 4 signal chains are summarized in Table.I.

Table 1. Basic PD meters parameters

\begin{tabular}{|c|c|c|c|c|}
\hline & \multicolumn{3}{|c|}{ PD meter signal chain } \\
\cline { 2 - 5 } & direct digitalization & \multicolumn{2}{c|}{ analogue } \\
\hline Parameter & $\begin{array}{c}\text { full } \\
\mathrm{BW}\end{array}$ & $\begin{array}{c}\text { partial } \\
\mathrm{BW}\end{array}$ & linear & $\begin{array}{c}\text { log. } \\
\text { reduction }\end{array}$ \\
\hline $\begin{array}{c}\text { ADC } \\
\text { sampling } \\
\text { frequency }\end{array}$ & $\begin{array}{c}500 \\
\mathrm{MHz}\end{array}$ & $39.6 \mathrm{MHz}$ & $\begin{array}{c}128 \\
\mathrm{kHz}\end{array}$ & $128 \mathrm{kHz}$ \\
\hline $\begin{array}{c}\text { ADC } \\
\text { resolution }\end{array}$ & $16 \mathrm{bit}$ & $16 \mathrm{bit}$ & $12 \mathrm{bit}$ & $12 \mathrm{bit}$ \\
\hline $\begin{array}{c}\text { Nominal } \\
\text { charge range }\end{array}$ & $10 \mathrm{nC}$ & $10 \mathrm{nC}$ & $10 \mathrm{nC}$ & $10 \mathrm{nC}$ \\
\hline $\begin{array}{c}\text { Uncertainty } \\
\text { of full scale }\end{array}$ & $0.03 \%$ & $0.50 \%$ & $0.20 \%$ & $0.27 \%$ \\
\hline $\begin{array}{c}\text { Dynamic } \\
\text { range }\end{array}$ & $75 \mathrm{~dB}$ & $93 \mathrm{~dB}$ & $87 \mathrm{~dB}$ & $69 \mathrm{~dB}$ \\
\hline
\end{tabular}

The table contains two fully digital signal chains one which digitizes the whole signal spectra and other for digitizing only the range described in [2]. There are some limitations in frequency range with 
respect to the commercial availability of the monolithic integrated circuit with high resolution and high sampling frequency.

In the table 1 . are also two analog signal chains with digitalization - one without logarithmic amplifier and the same chain improved with logarithmic amplifier for easy comparison. The improvement in dynamic range is dramatic and opens door for many measurements such as realtime predicting diagnostic systems for rotary machines in power plants.

\section{PARTIAL DISCHARGE MEASUREMENT CHAINS COMPARSION}

The four signal chains are compared. First traditional signal chain with peak detection circuit and low speed ADC. Second signal chain with logarithmic amplifier and peak detection circuit with low speed ADC. Third fully digital signal chain with narrowband digitalization and finally fourth signal chain with wideband digitalization of the PD signals.

The traditional analogue signal chains have limited dynamic range because of the peak detection circuits limits, but the electronic part of the design is relative simple.

The digital signal chains specially signal chain with digitalization of the full wideband signal, is complex digital signal chain and the parameters of the digital filters acquisition algorithms can be changed because a lot of computing parameters are the variables in the software.

All four signal chains can be used for on-line diagnostic measurements and can save lot of time and sources in maintenance of the high voltage units.

\section{CONCLUSION}

The paper presents traditional and modern ways in on-line diagnostic measurement of the health of the high voltage insulation system from electronic and data acquisition point of view. Four measurement chains are analyzed - two analog based and two digital based. All analyzed chains are compared with real components.

The area computing technique can be used in many other impulse measurements.

Because this technique is not able to recognize the shape of impulse, other additional techniques will be used such as a discrimination of pulses with long/short rise/fall time, packed pulses (pile-up rejection) etc.

\section{ACKNOWLEDGMENTS}

This project is supported by the research program No. MSM6840770015 Research of Methods and Systems for Measurement of Physical Quantities and
Measured Data Processing of the CTU in Prague and is sponsored by the Ministry of Education, Youth and Sports of the Czech Republic.

\section{REFERENCES}

[1] R. Schwarz, M. Muhr, S. Pack. Partial discharge detection in oil with optical methods. IEEE International Conference ICDL 2005, Coimbra, Portugal. June 2005, pp. 245-248.

[2] D. Dapeng, T. Letian; Q. Yong, W. Jiang, H. Chengjun, Z. Yi, J. Xiuchen. Experimental study and feature extraction on UHF partial discharge detection for typical model in air. International Conference on Condition Monitoring and Diagnosis, CMD 2008. 2008. April 2008, pp.1040-1043.

[3] P. Kundu, N. K. Kishore, A. K. Sinha. Simulation and analysis of acoustic wave propagation due to partial discharge activity. IEEE Conference on Electrical Insulation and Dielectric Phenomena”. Oct. 2006, pp.607610.

[4] Li Yanqing, Lu Fangcheng, Xin Baoan, Chen Zhiye. A new method using ultrasonic for partial discharge pattern recognition. International Conference on Power System Technology, Power Con 2002. 13-17 Oct. 2002, pp.1004-1007.

[5] C. Macia-Sanahuja, L. H. Rivera. Wavelet analysis of partial discharges acoustic waves obtained using an optical fiber interferometer sensor for transformer applications. IEEE International Symposium of Industrial Electronics, 2003. ISIE'03. June 2003, pp. 1071-1076.

[6] D. Koenig, Y. N. Rao. Partial Discharges in Electrical Power Apparatuses. VDE-Verlag; Germany, 1998; ISBN 3-8007-1760-3.

[7] EN 60270 High-voltage test techniques Partial discharge measurements; Prague 2001, Czech Normalized Institute, cat. Number 63384.

[8] A. Cavallini, G. C. Montanari, M. Olivieri, F. Puletti. Diagnostic evaluations of electrical apparatus by a novel partial discharge measurement system. International Conference on Power System Technology, volume 2, Nov. 2004, pp.1689-1693.

[9] M. Kriz, J. Vedral. Quantification of Partial Discharges Charge. 4th International Conference on Measurement 2003, Slovak Academy Sciences, 2003, pp. 407-410.

[10] M. Kriz, J. Vedral. Preprocessing circuits for partial discharges measurement. International Workshop on ADC Modelling and Testing IWADC 2003, University degli Studi di 
Perugia, 2003, pp. 201-203.

[11] M. Kriz, J. Vedral. Partial discharge meter. International Conference of Applied Electronics 2004, University of West Bohemia FEE, Pilsen, 2004, pp.124-126.

[12] K. Zalis. Partial discharges in insulating systems of electrical machines. Prague ACADEMIA, 2005, ISBN 80-200-1358-X.

[13] K. Zalis, L. Karasová-Beranova. Problems with partial discharge measurement disturbance elimination. Electric Power Conference EPVE 2008 [CD-ROM]. Brno: VUT v Brno, FEKT, 2008, pp.1-6. ISBN 978-80-7204-603-4.

[14] M. Kriz. Partial discharge measurement systems and methods optimalization, $P h D$. Thesis, CTU FEE, Prague 2009, (in Czech).

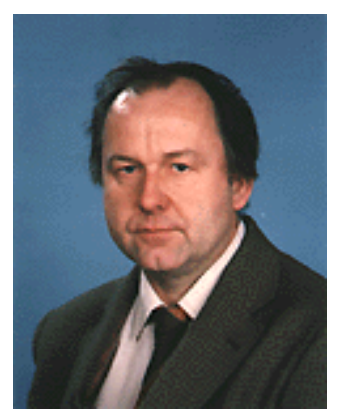

Assoc. prof. Ing. Josef Vedral, CSc. In 1971 finished CTU Prague, Faculty Electrical Engineering. In 1977 he got his CSc. degree; in 1991 he defended his habilitation thesis. He has been interested in analog and digital signal processing in measuring technology, special in chemistry, nuclear and energy instrumentation techniques. Is an author of 12 textbooks, 1 monograph and about 65 original articles and tutorials in internationals conferences and 12 patents in Czech Republic.

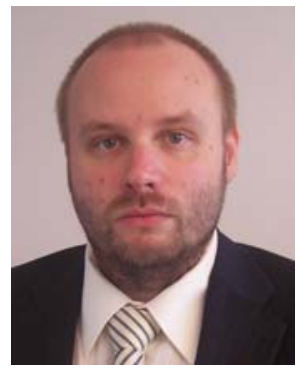

Ing. Martin Kriz, Ph.D. In 1998 finished CTU Prague, Faculty Electrical Engineering. From 2003 to 2005 has been PGS student in this faculty. In 2010 he got his Ph.D. degree. He has been interested in analog and digital signal processing in measuring technology.

Is a author of 8 original articles in internationals conferences proceedings.

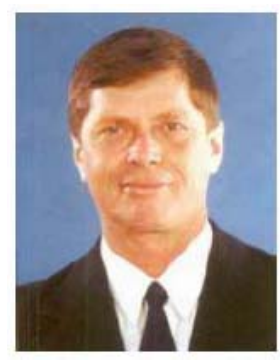

Assoc. prof. Ing. Karel Zalis, CSc. In 1969 finished CTU Prague, Faculty Electrical Engineering. In 1977 he got his CSc degree; in 2002 he defended his habilitation thesis. He has been interested in testing of energy machines with partial discharge methods.

Is an author of 6 textbooks, 1 monograph and about 46 original articles and tutorials in internationals conferences and 4 patents in Czech Republic. 